Graphical Abstract (for review)

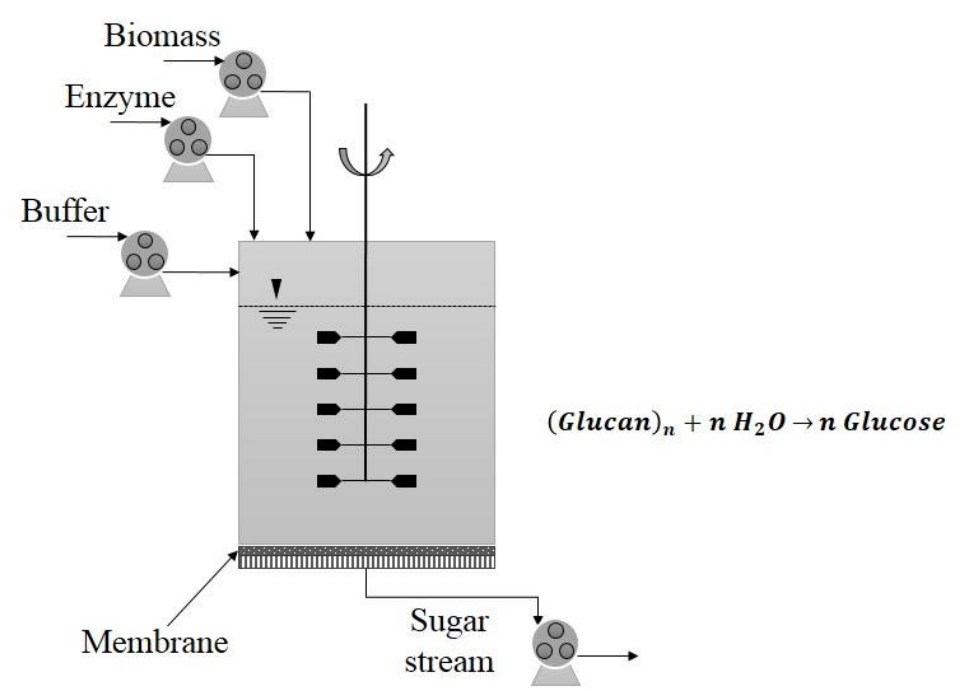

Graphical Abstract: Submerged membrane for continuous enzymatic hydrolysis 


\title{
Investigation of a submerged membrane reactor for continuous biomass hydrolysis
}

\author{
Mohammadmahdi Malmali ${ }^{*}$, Jonathan Stickel ${ }^{\#}$, S. Ranil Wickramasinghe*1 \\ * Ralph E. Martin Department of Chemical Engineering, University of Arkansas, \\ Fayetteville, AR 72701, USA \\ \# National Renewable Energy Laboratory, National Bioenergy Center, Golden, CO \\ 80401, USA
}

\begin{abstract}
Enzymatic hydrolysis of cellulose is one of the most costly steps in the bioconversion of lignocellulosic biomass. Use of a submerged membrane reactor has been investigated for continuous enzymatic hydrolysis of cellulose thus allowing for greater use of the enzyme compared to a batch process. The submerged $0.65 \mu \mathrm{m}$ polyethersulfone microfiltration membrane avoids the need to pump a cellulose slurry through an external loop. Permeate containing glucose is withdrawn at pressures slightly below atmospheric pressure. The membrane rejects cellulose particles and cellulase enzyme bound to cellulose. Here proofof-concept experiments have been conducted using a modified, commercially available membrane filtration cell under low fluxes around $75 \mathrm{~L} \mathrm{~m}^{-2} \mathrm{~h}^{-1}$. The operating flux is determined by the rate of glucose production. Maximizing the rate of glucose production involves optimizing mixing, reactor holding time, and the time the feed is held in the reactor prior to commencement of membrane filtration and continuous operation. Maximizing glucose production rates will require operating at low glucose concentration in order to minimize the adverse effects of product inhibition. Consequently practical

\footnotetext{
${ }^{1}$ Corresponding author: Tel: +1 479575 8475; Fax: +1 479575 4940; email: ranil.wickrmasinghe@ $@$ uark.edu
} 
submerged membrane systems will require a combined sugar concentration step in order to concentrate the product sugar stream prior to fermentation.

\section{Key words}

Biorefinery, cellulase enzyme, cellulose, microfiltration, ultrafiltration, product inhibition

\subsection{Introduction}

Increasing world energy usage as well as increasing environmental concerns relating to greenhouse gas emission combined with limited fossil fuel reserves has led to considerable interest in the development of economical and energy efficient processes for sustainable production of fuels and chemicals [1]. Plant biomass represents the only sustainable source of organic carbon [2]. Unlike $1^{\text {st }}$ generation biofuels, production of $2^{\text {nd }}$ generation biofuels from lignocellulosic biomass is far more complex. Development of new efficient separation and purification operations that lead to process intensification are essential for production of competitive $2^{\text {nd }}$ generation drop-in biofuels. Membrane-based separation processes are attractive as they could lead to significant process intensification and hence reduced operating costs [3].

Here we focus on hydrolysis of lignocellulosic biomass followed by fermentation. Figure 1 is a schematic representation of a future lignocellulosic biomass to biofuel biorefinery. The main processing steps are shown. The first step involves receiving and storage of the lignocellulosic biomass. The biomass is usually shredded into an appropriate particle size and then pumped as a slurry to the pretreatment reactor. A leading technology

for pretreatment is the use of dilute sulfuric acid at elevated temperatures [4,5]. Dilute 
sulfuric acid has been shown to effectively hydrolyze the hemicellulose component of the biomass to its monomeric sugars as well as enhance the enzymatic digestibility of cellulose [6]. After dilute acid pretreatment the $\mathrm{pH}$ of the hydrolysate is between 1 and 2. Further the presence of phenolics, acid soluble lignin, acetic acid and sugar degradation compound such as furfural (toxic compounds) in the hydrolysate can adversely affect the efficiency of the subsequent enzymatic hydrolysis and fermentation steps. Consequently the conditioning step adjusts the $\mathrm{pH}$ of the hydrolysate and sometimes removes toxic compounds.

Next, cellulose is typically enzymatically hydrolyzed to glucose in a batch process. A cocktail of cellulase enzymes is used to break down cellulose synergistically [7]. After enzymatic hydrolysis, the hydrolysate is fed to the fermentation reactor where the sugars are converted to the desired biofuel typically using microorganisms. Subsequent steps include product recovery, purification and storage. The purification operations used depend on the biofuel being produced. Given the large amount of water required to pump the lignocellulosic biomass slurry, water treatment and recovery are critical for an economically viable biorefinery.

This contribution considers the enzymatic hydrolysis step which is typically conducted in batch mode where the cellulase enzyme is used only once. However the cost of the enzymes has been an inhibitory factor for the commercialization of biomass conversion technology [8]. There is considerable variability in the cost and concentration of the cellulase enzyme that is considered to be economically viable. This variability stems from many factors, including feedstock type and delivery costs, the conversion technologies employed, and the price of the biofuels and bioproducts produced. The 
National Renewable Energy Laboratory suggests a cellulose loading of $20 \mathrm{mg}$ enzyme/g cellulose [9]. This amount of enzyme accounts for $\sim 0.16 \%$ ( $\$ 0.35 / \mathrm{gal}$ ethanol) of the minimum ethanol selling price. The United States Department of Energy has set a goal of \$ 0.12/gal ethanol.as the enzyme selling price [9]. These numbers highlight the importance of maximizing enzyme recycle and reuse. Increasing the usage efficiency of the enzyme is highly desirable. Thus development of a continuous enzymatic hydrolysis process where the cellulase enzymes may be reused is of considerable interest.

A further complication with batch hydrolysis of cellulose is that the conversion rate is often limited by product inhibition (i.e. inhibited by glucose and cellobiose). Using Celluclast, Novozymes A/S (Bagsvaerd, Denmark) cellulase enzyme, Andrić et al. [10] indicate that the presence of glucose significantly reduced enzymatic hydrolysis rates. Removal of glucose leads to increased glucose yields and rates of production. Combination of a membrane separation unit with a hydrolysis reactor could enable continuous removal of glucose and recycle of cellulase enzyme and residual cellulose. Here we focus on the development of a combined membrane separation unit and a hydrolysis reactor that could enable continuous enzymatic hydrolysis of lignocellulosic biomass.

Abels et al. [11] provide an excellent review of membrane processes for biorefinery applications. Several studies [12-17] have focused on the use of ultrafiltration membranes for continuous removal of glucose in the permeate. The retentate containing residual cellulase enzyme and cellulose is recycled to the enzyme reactor. Mores et al. [18] have considered the use of sedimentation and microfiltration for recovery of cellulase enzyme. They indicate that by using $0.22 \mu \mathrm{m}$ pore size membranes, $75 \%$ of the cellulase enzyme 
(46-100 kDa MW) could be recycled in active form due to the fact that the majority of the enzyme is bound to the biomass. The much lower pressures required for microfiltration (up to $100 \mathrm{kPa}$ ) is a significant benefit resulting in lower operating costs. Andrić et al. [19] provide several insights into the design of membrane bioreactors for enzymatic hydrolysis of lignocellulosic biomass. Since cellulose is insoluble, pumping high-solids concentration feed streams is problematic due to the high solution viscosity. Further membrane fouling is a serious concern at high solids loadings.

Carstensen et al. [20] have reviewed the use of membranes for in situ product recovery. Two modes of operation exist: external loop membranes and submerged membranes. Figure 2 gives a schematic representation of an external loop and submerged membrane reactor. Numerous configurations have been described for both external loop [21-25] and submerged membranes [26-29]. In both modes of operation, the reactor volume is kept constant by adding fresh feed (cellulase enzyme and biomass suspended in buffer) at the same rate at which permeate is removed.

External loop membranes involve pumping the contents of the enzyme reactor through a membrane module. Retentate is recycled back to the reactor while the permeate containing glucose is continuously removed. All configurations require pressurizing and pumping the feed (a slurry containing insoluble cellulose) through the membrane module. The permeate is generally removed at close to atmospheric pressure.

Submerged membranes on the other hand involve placing the membrane inside the enzyme reactor (Figure $2 b$ ). Thus, there is no need to pump the contents of the enzyme reactor through an external loop. Further, pressurization of the feed is not required as the permeate is withdrawn at sub-atmospheric pressure. Difficulties involved with pumping 
high viscosity non-Newtonian biomass slurries are avoided. In addition, by ensuring rapid mixing membrane fouling due to deposition of cellulose and cellulase enzyme on the membrane surface is minimized. Commercial use of submerged membrane reactors has been limited due to scale up difficulties and a lack of commercial units [30].

Here we have investigated the development a submerged membrane reactor for continuous enzymatic hydrolysis of lignocellulosic biomass. Submerged membrane bioreactors are routinely used for waste treatment and have been shown to be economical and robust. We have used $\alpha$-cellulose as a model feed stream as it has been used by previous investigators and avoids complications due to the accumulation of lignin. We have investigated the use of a microfiltration membrane to reject cellulose and adsorbed cellulase enzyme in the retentate which is recycled back to the reactor. We show that the rate of hydrolysis of $\alpha$-cellulose can be up to an order of magnitude higher in a continuous hydrolysis process compared to a batch process. Further by recycling the enzyme, enzyme usage efficiency is increased.

\subsection{Materials and Method}

All chemicals were ACS reagent grade. D-glucose, $\alpha$-cellulose and Whatman No. 1 filter paper were purchased from Sigma Aldrich (St. Louis, MO). Sodium azide 5\% w/v, acetic acid and sulfuric acid were purchased from Seastar Chemicals Inc. (Sidney, BC, Canada). Sodium hydroxide and citric acid were purchased from J. T. Baker (Philipsburg, NJ). Multi-enzyme cocktail Cellic CTec2 was generously provided by Novozymes North America (Franklinton, NC). Sodium potassium tartrate and 3,5 dinitrosalicylic acid were 
purchased from Alfa Aesar (Ward Hill, MA), phenol and sodium metabisulfite was purchased from Amresco (Solon, $\mathrm{OH}$ ). Microfiltration membranes, $0.65 \mu \mathrm{m}$ polyethersulfone, were obtained from Pall Corporation (Port Washington, NY). Deionized water (conductivity $<10 \mu \mathrm{Scm}^{-1}$ and resistance $>18.5 \mathrm{M} \Omega$ ) was obtained from a Labconco (Kansas City, MO) water purification system (Water Pro RO and Water Pro PS Polishing Stations).

\subsection{Enzymatic hydrolysis}

Initial batch experiments were conducted in order to determine an appropriate temperature and $\mathrm{pH}$ for hydrolysis. Centrifuge tubes were loaded with $4 \mathrm{~g}$ of $\alpha$-cellulose, $0.2 \mathrm{~g} \mathrm{CTec} 2$ enzyme, and $38.5 \mathrm{ml}$ of $50 \mathrm{mM}$ citric acid buffer with $\mathrm{pH}$ in the range of 3.85.5. The $\mathrm{pH}$ was adjusted using $0.1 \mathrm{M}$ sodium hydroxide and sulfuric acid. The tubes were sealed and incubated on a shaker table at temperature between $40-60{ }^{\circ} \mathrm{C}$ for 2 and 4 days. The shaker table was set at $150 \mathrm{rpm}$. Based on the results of these experiments all batch and continuous hydrolysis experiments were conducted at $50{ }^{\circ} \mathrm{C}$ and $\mathrm{pH} 4.8$.

Tables 1 and 2 summarize the various batch and continuous hydrolysis experiments.

Batch experiments were conducted in a 1 L flask. A RZR1 Brinkmann Heidolph (Elk Grove Village, IL) mechanical overhead stirrer equipped with a Heidolph PR30 pitched blade impeller was used to provide the required agitation. In all batch tests (experiments $1-4$, Table 1), the initial cellulose loading was $100 \mathrm{~g} / \mathrm{L}$ and the cellulase enzyme loading was 25 or $50 \mathrm{mg}$ enzyme/g cellulose. Cellulose and cellulase enzyme were suspended in $50 \mathrm{mM}$ citric acid buffer at $\mathrm{pH}$ 4.8. The feed volume was $1000 \mathrm{~mL}$. Sodium azide, $0.1 \mathrm{w} / \mathrm{v}$ $\%$, was added to suppress bacterial growth. 
Each experiment was run for at least 85 hours. Stirring speeds of 100 and $600 \mathrm{rpm}$ were investigated. Samples $(2 \mathrm{~mL})$ were collected at various time intervals and glucose concentration determined. All samples were filtered using $0.22 \mu \mathrm{m}$ syringe filter and the glucose concentration determined using HPLC as described in Section 2.2. After each 24 hour period, 25-50 mL DI water was added to compensate for evaporation.

Continuous hydrolysis experiments were conducted using a modified Millipore EMD 8400 stirred cell (Billerica, MA) as the membrane reactor. The membrane was housed at the bottom of the reactor. The cell was modified by attaching an extension to the top of the cell thus increasing the volume to $1.5 \mathrm{~L}$. In addition, in order to ensure good mixing, a modified Heidolph PR30 pitched blade impeller was used by adding an extra set of blades to the shaft.

In all continuous experiments the initial cellulose loading was either 100 or $150 \mathrm{~g} / \mathrm{L}$ and the initial cellulase enzyme loading was $50 \mathrm{mg}$ enzyme/g cellulose (see Table 2). Cellulose was added first and incubated for 24 hours to ensure it was fully hydrated. Next cellulase enzyme was added. In experiments 5-7 filtration was started immediately after addition of the cellulase enzyme. In experiments 8 and 9 the contents of the reactor were incubated (pre-holding time) for 5 hours while in experiment 10 the pre-holding time was 0.5 hour (see Table 1$)$.

Permeate was withdrawn using a Masterflex peristaltic variable speed drive (Model 7528-30, Cole Parmer, Vernon Hills, IL) equipped with pump head for L/S 24 tubing (Cole Parmer, Vernon Hills, IL). As the reactor is open to the atmosphere, the permeate is withdrawn at sub-atmospheric pressure. The permeate flow rates for different experiments are given in Table 2. Two Masterflex peristaltic variable speed drives were used as feed 
pumps (Model 7528-30, Cole Parmer, Vernon Hills, IL), one to pump cellulose and the other to pump cellulase enzyme (equipped with L/S 24 and 13 tubing pump head, respectively). Cellulose and cellulase enzyme stock solutions were prepared. The concentration of feed stock solution was calculated in order to produce a cellulose concentration of $25 \mathrm{~g} / \mathrm{L}$ and cellulase concentration of 4 and $10 \mathrm{mg}$ enzyme/g cellulose (for continuous tests with 1 and 10 hours holding time, respectively) after mixing both feed streams. As described for batch experiments, samples $(2 \mathrm{~mL})$ were collected at various time intervals and glucose concentration determined (Section 2.2). In addition, samples were periodically collected for determination of total suspended solids (TSS) as descried in Section 2.3.

Holding times of 1 and 10 hours were investigated (see Table 2). Holding time is defined as the reactor volume divided by the permeate flow rate. The holding time was varied by varying the permeate flow rate and reactor volume. The reactor volume was 1.2 $\mathrm{L}$ and $300 \mathrm{~mL}$ for holding times of 10 hours and 1 hour respectively.

\subsection{HPLC analysis}

Glucose concentration was determined using an Agilent 1200 series HPLC (Agilent Technologies, Palo Alto, CA) equipped with an Agilent $6.5 \times 300 \mathrm{~mm}$ Hi-Plex Ca (Duo) column and an Agilent refractive index detector (RID). The RID sample cell was set at 55 $\square$ C. The mobile phase appropriate for this column was HPLC grade water with flow rate set at $0.6 \mathrm{~mL} \mathrm{~min}^{-1}$. The auto sampler was set to an injection volume of $15 \mu \mathrm{L}$ and the column was kept at $80 \square \mathrm{C}$ using a thermostatic column compartment. A series of 
calibration standards and calibration verification standards (CVS) were obtained from Absolute Standards Inc., Hamden, CT. All measurements were taken in triplicate and average results are reported.

\subsection{Total suspended solids determination}

In continuous experiments, total suspended solids was determined by filtering a 4 $\mathrm{mL}$ sample of the reactor contents in a Corning Costar Spin-X centrifuge tube filters (Sigma Aldrich) at a spin speed of 10,000 rpm for 5 minutes. Next contents of each filter insert were rinsed and washed with $1 \mathrm{~mL}$ of DI water, followed by spinning at 10,000 rpm for 5 minutes. This washing procedure was repeated 3 times. The insert filters were dried in a VWR Symphony Vacuum Oven (Radnor, PA) at $35{ }^{\circ} \mathrm{C}$ for 24 hours. TSS may be calculated from the following expression. $\mathrm{TSS}=\left(\mathrm{M}_{\mathrm{filter}}\right.$, dried $\left.-\mathrm{M}_{\text {filrer,initially }}\right) / \mathrm{V}_{0}$ where $\mathrm{M}_{\text {filter,dried }}$ and $\mathrm{M}_{\text {filter,initially }}$ are the weight of filter after drying in the oven and before use and $\mathrm{V}_{0}$ is the volume of the sample loaded in the centrifuge tube.

\subsection{Results and Discussion}

Figure 3 gives the batch hydrolysis results. Solid lines and filled symbols give the glucose concentration as a function of time (left-hand-side y-axis) while dashed lines and open symbols give the rate of glucose production as a function of time (right-hand-side yaxis). All four experimental runs indicate that the rate of glucose production decreases rapidly with increasing glucose concentration, highlighting the adverse effects of product inhibition. Higher initial cellulase loadings and stirring speeds lead to higher glucose concentrations for a given reaction time. This result highlights the importance of good 
mixing of the cellulose and cellulase enzyme to ensure binding of the cellulase enzyme on to the cellulose.

Figures 4 and 5 give results for continuous hydrolysis experiments. In all experiments the stirring speed was $100 \mathrm{rpm}$. While the batch experiments indicate that higher stirring speeds are advantageous as they lead to better mixing and faster rates of glucose hydrolysis, practical considerations are likely to limit the maximum feasible stirring rate [31-33].

Figure 4 gives results for experiments 5-7 where no pre-holding time was used. Figure 5 gives results for experiments 8-10 which included a pre-holding time. In both figures the glucose concentration, cellulose concentration and the rate of glucose production as a function of time are given.

Figure 4 shows that the rate of glucose production for the three runs that did not include any pre-holding time are similar. The lowest glucose concentration is obtained for the experiment with the lower ( 1 hour) holding time (experiment 7$)$. In these experiments a microfiltration membrane was used. It will take some time for the cellulase enzyme to bind to the cellulose present. Free cellulase enzyme will not be rejected by the membrane. Consequently there will be a significant loss of cellulase enzyme in the permeate for tests with lower holding time. Increasing the holding time will increase the average residence time of the enzyme in the reactor and increase the likelihood of enzyme binding to the cellulose present. Thus the steady state glucose concentration is lowest for the experiment which had the lower holding time.

Figure 4 indicates that in the absence of a preholding step, the glucose concentration decreases for a cellulose loading of $150 \mathrm{~g} / \mathrm{L}$ but decreases for an initial cellulose loading of 
$100 \mathrm{~g} / \mathrm{L}$ before reaching a steady state value. A continuous process will be much more difficult to control than a batch process. Here, since only bound cellulase enzyme is rejected, the initial cellulose loading as well as enzyme concentration and degree of mixing will affect the amount of early washout of the enzyme and hence a drop in the steady state glucose concentration as observed in experiment 4 (blue circles). In designing a practical system it will be essential to understand the relationship between the initial conditions and the final steady state operating condition as well as the stability of the steady state conditions to small perturbations in operating conditions.

The final steady state rate of glucose production is similar for all three runs though the initial steady state rate is higher for experiments 5 and 7 . In the case of experiment 5 , a higher cellulose loading of $150 \mathrm{~g} / \mathrm{L}$ was used which could explain the higher initial rate of glucose production. The higher initial rate of glucose production for experiment 7 may reflect the effects of product inhibition as this is the run that displayed the lowest glucose concentration. The final steady state cellulose concentration is similar for all three experiments though the initial cellulose concentration is higher for experiment 5 .

The results for experiments 8-10 that include a pre-holding time show more substantial differences. Initial glucose concentrations for experiments 8 and 9 are much higher compared to results with no pre-holding time. Since a microfiltration membrane is used, which does not reject free cellulase enzyme, it is essential that a pre-holding time be incorporated in order to allow binding of the cellulase enzyme to the cellulose present. The highest initial glucose concentrations and cellulose concentrations are observed for experiment 8 which had the highest initial cellulose loading of $150 \mathrm{~g} / \mathrm{L}$. As expected, the 
lowest initial glucose concentration is obtained for experiment 10 which had the lower preholding time of 0.5 hour.

The results in Figure 5 indicate that at steady state the glucose concentration drops to between 10 and $20 \mathrm{~g} / \mathrm{L}$ for all three runs. While the steady state glucose concentration is only a little lower in the absence of a pre-holding time (Figure 4), the rate of glucose production is significantly higher. This is significant as not only is it possible to increase enzyme usage, but also the rate of glucose production. In a continuous process operating at lower glucose concentrations, one avoids the adverse effects of product inhibition. By comparing Figures 3 and 5 it can be seen that in batch operation, after 20 hours, the rate of glucose production can be up to an order of magnitude lower compared to continuous processing. This result is in agreement with earlier studies [34,35]. Smith et al. [36] found that increasing glucose concentration from 7 to $48 \mathrm{~g} / \mathrm{L}$ leads to $94 \%$ reduction in enzyme activity.

Figure 5 indicates that if one incorporates a pre-holding time, the steady state glucose concentration drops compared to the initial value. As expected, this is not observed in the absence of any pre-holding time as there is little time for cellulase to bind to and hydrolyze the cellulose present prior to the commencement of membrane filtration. The result of experiment 10 is particularly interesting as it displays the lowest steady state glucose concentration and the lowest decrease from the initial glucose concentration while maintaining the highest rate of glucose production. In this experiment the pre-holding time was 0.5 hour and the holding time was 1 hour. The result highlights the importance of glucose inhibition on hydrolysis, as well as the interplay between pre-holding time and holding time when maximizing the rate of hydrolysis. The results further highlight the 
importance of optimizing the enzyme concentration and the ratio of enzyme to cellulose in the initial feed that is charged to the rector as well as during continuous operation. Typically, in batch hydrolysis tests, $20-40 \mathrm{mg}$ enzyme/g cellulose is used. In a recent process design and economic analysis report a goal of $20 \mathrm{mg}$ enzyme/g cellulose is stated [9]. As a result, recycle and reuse of enzyme led to higher efficiency of enzymatic hydrolysis process.

The glucose concentration in the reactor has a strong effect on the rate of hydrolysis. Previous studies have highlighted the importance of product inhibition [10]. Comparing experiments 6 and 7 in Figure 4 and 9 and 10 in Figure 5 it can be seen that increasing the glucose concentration from 5 to $18 \mathrm{~g} / \mathrm{L}$ resulted in a large decrease in the rate of glucose production.

While previous studies [19] have indicated the benefits of continuous enzymatic hydrolysis of cellulose, design of a membrane based system has been problematic. Use of an external loop membrane is complicated as pumping a cellulose slurry is challenging [37,38]. Further use of an ultrafiltration membrane that rejects cellulase enzyme requires high feed pressures that could lead to much higher pumping costs. Here we have designed a submerged membrane reactor that avoids the need to pump a cellulose slurry through an external loop. By using a microfiltration membrane we withdraw permeate at pressures slightly below atmospheric pressure. Thus high pressure pumping costs are avoided.

The results obtained here provide a number of insights into the design of a submerged membrane reactor for continuous biomass hydrolysis. The increased efficiency of enzyme usage can be clearly noted from the difference between the initial enzyme loading of $50 \mathrm{mg}$ enzyme/g cellulose and the rate of enzyme addition during continuous 
operation which was either 4 or $10 \mathrm{mg}$ enzyme/g cellulose injected. Loss of enzyme is due to deactivation as well as flow through the membrane pores of unbound enzyme.

Zhang et al. [39] have proposed the use of a submerged ultrafiltration membrane reactor (10 $\mathrm{kDa}$ nominal molecular weight cut off). Transmembrane pressures between 0.6 and 1 bar were used, requiring pressurization of the feed. While use of an ultrafiltration membrane will minimize loss of unbound cellulase, the additional equipment costs involved in the use of a pressurized fermentation reactor must also be considered.

It should also be noted that in general low-solids concentrations must be used when using an external loop membrane due to the difficulties involved in pumping a slurry consisting of cellulose. Since microfiltration membranes only reject cellulase enzyme bound to cellulose, using a microfiltration membrane in an external loop may lead to higher cellulase losses. By using higher cellulose loading in a submerged membrane reactor it is likely that higher enzyme recovery will result. This again highlights the importance of optimizing holding time. Further glucose will be continuously removed in the permeate ensuring a low glucose concentration in the hydrolysis reactor. This will minimize inhibition of the cellulase enzyme by glucose and maximize the rate of glucose production.

As indicated in Figures 4 and 5, in continuous operation, the glucose concentration in the permeate will be too low for direct introduction to the fermentation reactor. Fermentation reactors usually operate at total sugar concentration of 150 to $250 \mathrm{~g} / \mathrm{L}$. As a result, concentration of the sugars in the permeate (by factor of 6 to 10) will be necessary before fermentation. In earlier work we have investigated the use of a nanofiltration membrane to concentrate sugars and remove inhibitory compounds from biomass hydrolysates prior to fermentation [40]. Incorporation of a nanofiltration membrane into 
the permeate stream from the submerged membrane reactor could enable the development of a practical system.

When using a submerged membrane reactor at atmospheric pressure the permeate will always be withdrawn at subatmospheric pressure. Consequently the maximum pressure driving force that can be generated is less than 1 atmosphere. The microfiltration membrane used here has a very large water permeability of around 44,000 $\mathrm{L} \mathrm{m}^{-2} \mathrm{~h}^{-1} \mathrm{bar}^{-1}$. The permeate flux in the experiments conducted here was around $70 \mathrm{~L} \mathrm{~m}^{-2} \mathrm{~h}^{-1}$ indicating a very low transmembrane pressure drop. Thus the pump was used to control the permeate flux. This result indicates that in practice much higher permeate fluxes could be obtained and pumping costs will be negligible.

Pressurizing the feed will enable the use of larger transmembrane pressures which could lead to higher fluxes. Further it could enable the use of higher pressure membranes such as low molecule weight cut off ultrafiltration membranes, enabling rejection of free cellulase enzyme in solution leading to even greater cellulase recovery. However, the cost of conducting enzymatic hydrolysis in a pressurized vessel is likely more than any cost savings that might be achieved.

The results obtained here indicate the importance of optimizing the process in order to maximize the rate of glucose production. Important parameters include: cellulase enzyme and cellulose loading, pre-holding and holding times as well as stirring. In an optimized process one would aim to maximize enzyme usage and the rate of glucose production. 
In this work we have used $\alpha$-cellulose as a model feed stream. The results obtained here provide many insights into the design of a practical submerged membrane system. However, for real lignocellulosic substrates residual lignin will have to be removed. This will involve careful design of the pretreatment process $[39,41]$ in order to minimize the amount of insoluble lignin present. In addition intermittent discharge of the accumulated solids from the submerged membrane reactor will be required.

All membrane processes suffer from fouling. Here little fouling was observed due to the fact that a model feed stream consisting of $\alpha$-cellulose was used. However use of real feed streams which contain significant amounts of hemicellulose and lignin are likely to be much more fouling. Thus membrane fouling studies and appropriate cleaning protocols will have to be developed. In determining the viability of a practical submerged membrane reactor for continuous biomass hydrolysis it is essential to consider the entire integrated process which will include a sugar concentration step as well as lignin removal.

While the results obtained here indicate the feasibility of recycling the enzyme using a submerged membrane process, more detailed studies will be needed for specific feed streams and operating conditions before the commercial viability of introducing a submerged membrane process can be assessed. Specific information on optimized operating pressures, reduction in enzyme activity over time etc. will have to be determined for specific applications. In addition a lifecycle assessment and economic analysis is needed. Besides savings in enzyme cost the effect on the entire process must be considered. Such an analysis will indicate optimal enzyme loadings for an economically viable process. 


\subsection{Conclusions}

A submerged membrane reactor using a microfiltration membrane enables the continuous enzymatic hydrolysis of cellulose. The need to pump a slurry containing cellulose through external loop is avoided as is the need for high pressure pumps. Since only cellulase enzyme bound to cellulose is rejected by the microfiltration membrane, a pre-holding time is essential to permit binding of the enzyme to the cellulose. Maximizing glucose production rates will require optimizing the pre-holding time, holding time and stirring. A glucose concentration step will be required as the reactor is run at a low glucose concentration in order to avoid product inhibition.

\subsection{Acknowledgements}

This work was funded by the U.S. Department of Energy (Contract No. DE-AC3608-GO28308) and the National Renewable Energy Laboratory via subcontract AFA-111658-01.

\subsection{References}

[1] G.W. Huber, S. Iborra, A. Corma, Synthesis of transportation fuels from biomass: chemistry, catalysts, and engineering, Chem. Rev. 106 (2006) 4044-98.

[2] C. Wyman, S. Decker, M. Himmel, J. Brady, C. Skopec, L. Viikari, Hydrolysis of Cellulose and Hemicellulose, in: S. Dumitriu (Ed.), Polysaccharides, CRC Press, New York, 2004. 
[3] E. Drioli, A. Brunetti, G. Di Profio, G. Barbieri, Process intensification strategies and membrane engineering, Green Chem. 14 (2012) 1561-1572.

[4] D.J. Schell, J. Farmer, M. Newman, J.D. McMillan, Dilute-sulfuric acid pretreatment of corn stover in pilot-scale reactor: investigation of yields, kinetics, and enzymatic digestibilities of solids, Appl. Biochem. Biotechnol. 105 -108 (2003) 69-85.

[5] J. Shekiro, E.M. Kuhn, N.J. Nagle, M.P. Tucker, R.T. Elander, D.J. Schell, Characterization of pilot-scale dilute acid pretreatment performance using deacetylated corn stover, Biotechnol. Biofuels. 7 (2014) 23.

[6] D.L. Grzenia, S.R. Wickramasinghe, D.J. Schell, Fermentation of reactivemembrane-extracted and ammonium-hydroxide-conditioned dilute-acid-pretreated corn stover, Appl. Biochem. Biotechnol. 166 (2012) 470-478.

[7] M.E. Himmel, S.-Y. Ding, D.K. Johnson, W.S. Adney, M.R. Nimlos, J.W. Brady, et al., Biomass recalcitrance: engineering plants and enzymes for biofuels production, Science. 315 (2007) 804-807.

[8] C.E. Wyman, What is (and is not) vital to advancing cellulosic ethanol, Trends Biotechnol. 25 (2007) 153-7.

[9] D. Humbird, R. Davis, L. Tao, C. Kinchin, D. Hsu, A. Aden, et al., Process design and economics for biochemical conversion of lignocellulosic biomass to ethanol dilute-acid pretreatment and enzymatic hydrolysis of corn stover, National Renewable Energy Laboratory, Golden, CO, (2011).

[10] P. Andrić, A.S. Meyer, P.A. Jensen, K. Dam-Johansen, Effect and modeling of glucose inhibition and in situ glucose removal during enzymatic hydrolysis of pretreated wheat straw, Appl. Biochem. Biotechnol. 160 (2010) 280-297. 
[11] C. Abels, F. Carstensen, M. Wessling, Membrane processes in biorefinery applications, J. Memb. Sci. 444 (2013) 285-317.

[12] R.G. Henley, R.Y.K. Yang, P.F. Greenfield, Enzymatic saccharification of cellulose in membrane reactors, Enzyme Microb. Technol. 2 (1980) 206-208.

[13] F. Alfani, D. Albanesi, M. Cantarella, V. Scardi, A. Vetromile, Kinetics of enzymatic saccharification of cellulose in a flat-membrane reactor, Biomass. 2 (1982) 245253.

[14] I. Ohlson, G. Trägårdh, B. Hahn-Hägerdal, Enzymatic hydrolysis of sodiumhydroxide-pretreated sallow in an ultrafiltration membrane reactor, Biotechnol. Bioeng. 26 (1984) 647-653.

[15] S. Kinoshita, J.W. Chua, N. Kato, T. Yoshida, H. Taguchi, Hydrolysis of cellulose by cellulases of Sporotrichum cellulophilum in an ultrafilter membrane reactor, Enzyme Microb. Technol. 8 (1986) 691-695.

[16] K. Bélafi-Bakó, A. Koutinas, N. Nemestóthy, L. Gubicza, C. Webb, Continuous enzymatic cellulose hydrolysis in a tubular membrane bioreactor, Enzyme Microb. Technol. 38 (2006) 155-161.

[17] Q. Gan, S.J. Allen, G. Taylor, Design and operation of an integrated membrane reactor for enzymatic cellulose hydrolysis, Biochem. Eng. J. 12 (2002) 223-229.

[18] W.D. Mores, J.S. Knutsen, R.H. Davis, Cellulase Recovery via Membrane Filtration, Appl. Biochem. Biotechnol. 91-93 (2001) 297-309.

[19] P. Andrić, A.S. Meyer, P.A. Jensen, K. Dam-Johansen, Reactor design for minimizing product inhibition during enzymatic lignocellulose hydrolysis: II. 
Quantification of inhibition and suitability of membrane reactors, Biotechnol. Adv. 28 (2010) 407-425.

[20] F. Carstensen, A. Apel, M. Wessling, In situ product recovery: Submerged membranes vs. external loop membranes, J. Memb. Sci. 394-395 (2012) 1-36.

[21] M. Nakajima, T. Shoji, H. Nabetani, Protease hydrolysis of water soluble fish proteins using a free enzyme membrane reactor, Process Biochem. 27 (1992) 155-160.

[22] R.A. Korus, A.C. Olson, Use of glucose isomerase in hollow fiber reactors, J. Food Sci. 42 (1977) 258-260.

[23] F. Sannier, J.-M. Piot, P. Dhulster, D. Guillochon, Stability of a mineral membrane ultrafiltration reactor for peptide hydrolysis of hemoglobin, J. Chem. Technol. Biotechnol. 61 (1994) 43-47.

[24] P. Pasta, G. Carrea, E. Monzani, N. Gaggero, S. Colonna, Chloroperoxidasecatalyzed enantioselective oxidation of methyl phenyl sulfide with dihydroxyfumaric acid/oxygen or ascorbic acid/oxygen as oxidants, Biotechnol. Bioeng. 62 (1999) 489-493.

[25] S. Bouhallab, C. Touzé, Continuous hydrolysis of caseinomacropeptide in a membrane reactor: kinetic study and gram-scale production of antithrombotic peptides, Lait. 75 (1995) 251-258.

[26] M. Prata-Vidal, S. Bouhallab, G. Henry, P. Aimar, An experimental study of caseinomacropeptide hydrolysis by trypsin in a continuous membrane reactor, Biochem. Eng. J. 8 (2001) 195-202.

[27] V. Cauwenberg, P. Vergossen, A. Stankiewicz, H. Kierkels, Integration of reaction and separation in manufacturing of pharmaceuticals: Membrane-mediated production of Sibuprofen, Chem. Eng. Sci. 54 (1999) 1473-1477. 
[28] L. Greiner, D.H. Müller, E.C.D. van den Ban, J. Wöltinger, C. Wandrey, A. Liese, Membrane Aerated Hydrogenation: Enzymatic and Chemical Homogeneous Catalysis, Adv. Synth. Catal. 345 (2003) 679-683.

[29] Y. Isono, H. Nabetani, M. Nakajima, Preparation of lipase-surfactant complex for the catalysis of triglyceride hydrolysis in heterogeneous reaction systems, Bioprocess Eng. 15 (1996) 133-137.

[30] L.-E. Shi, G.-Q. Ying, Z.-X. Tang, J.-S. Chen, W.-Y. Xiong, H. Wang, Continuous enzymatic production of $5^{\prime}$-nucleotides using free nuclease P1 in ultrafiltration membrane reactor, J. Memb. Sci. 345 (2009) 217 - 222.

[31] D. Stark, U. von Stockar, In situ product removal (ISPR) in whole cell biotechnology during the last twenty years, in: U. Stockar, L.A.M. Wielen (Eds.), Process Integr. Biochem. Eng., Springer Berlin Heidelberg, Berlin/Heidelberg, 2003: pp. 10051015.

[32] L. Wang, T. Khan, K. Mohanty, R. Ghosh, Cascade ultrafiltration bioreactorseparator system for continuous production of $\mathrm{F}\left(\mathrm{ab}^{\prime}\right) 2$ fragment from immunoglobulin $\mathrm{G}$, J. Memb. Sci. 351 (2010) 96 - 103.

[33] H. Jørgensen, J.B. Kristensen, C. Felby, Enzymatic conversion of lignocellulose into fermentable sugars: challenges and opportunities, Biofuels, Bioprod. Biorefining. 1 (2007) 119-134.

[34] Y. Kim, E. Ximenes, N.S. Mosier, M.R. Ladisch, Soluble inhibitors/deactivators of cellulase enzymes from lignocellulosic biomass, Enzyme Microb. Technol. 48 (2011) 408415. 
[35] L.J. Jönsson, B. Alriksson, N.-O. Nilvebrant, Bioconversion of lignocellulose: inhibitors and detoxification., Biotechnol. Biofuels. 6 (2013) 16.

[36] B.T. Smith, J.S. Knutsen, R.H. Davis, Empirical evaluation of inhibitory product, substrate, and enzyme effects during the enzymatic saccharification of lignocellulosic biomass, Appl. Biochem. Biotechnol. 161 (2010) 468-482.

[37] C.M. Roche, C.J. Dibble, J.S. Knutsen, J.J. Stickel, M.W. Liberatore, Particle concentration and yield stress of biomass slurries during enzymatic hydrolysis at highsolids loadings., Biotechnol. Bioeng. 104 (2009) 290-300.

[38] J.J. Stickel, J.S. Knutsen, M.W. Liberatore, W. Luu, D.W. Bousfield, D.J. Klingenberg, et al., Rheology measurements of a biomass slurry: an inter-laboratory study, Rheol. Acta. 48 (2009) 1005-1015.

[39] M. Zhang, R. Su, Q. Li, Q. Qi, Z. He, Enzymatic saccharification of pretreated corn stover in a fed-batch membrane reactor, Bioenerg. Res. 4 (2011) 134-140.

[40] M. Malmali, J.J. Stickel, S. Ranil Wickramasinghe, Sugar concentration and detoxification of clarified biomass hydrolysate by nanofiltration, Sep. Purif. Technol. 132 (2014) 655-665.

[41] S.-G. Lee, H.-S. Kim, Optimal operating policy of the ultrafiltration membrane bioreactor for enzymatic hydrolysis of cellulose, Biotechnol. Bioeng. 42(6) (1993) 737-746. 


\section{Figure Captions}

Figure 1: Schematic representation of a future lignocellulosic biomass to biofuel biorefinery. A possible continuous hydrolysis step with enzyme recycle has been included.

Figure 2: Schematic representation of an external loop (a) and submerged membrane reactor $(b)$.

Figure 3: Batch hydrolysis results. Results are given for the 4 experiments listed in Table 1. Solid lines and filled symbols give the glucose concentration and are read using the left hand side y-axis; dashed lines and open symbols give the rate of glucose production and are read using the right hand side y-axis.

Figure 4: Continuous hydrolysis results. Results are given for experiments 5-7 listed in Table 2 which do not include a pre-holding time: (a) glucose concentration with filled symbols and solid lines; (b) cellulose concentration with filled symbols and dashed lines; (c) rate of glucose production with open symbols and solid lines.

Figure 5: Continuous hydrolysis results. Results are given for experiments 8-10 listed in Table 2 which included a pre-holding time: (a) glucose concentration with filled symbols and solid lines; (b) cellulose concentration with filled symbols and dashed lines; (c) rate of glucose production with open symbols and solid lines.

\section{Tables}


Table 1: Batch hydrolysis experiment details. In all experiments the initial cellulose loading was $100 \mathrm{~g} / \mathrm{L}$.

Table 2: Continuous hydrolysis experiment details. In all experiments the initial cellulase enzyme loading was $50 \mathrm{mg}$ enzyme/g cellulose. Fresh feed consisting of $25 \mathrm{~g} / \mathrm{L}$ cellulose and 4 and $10 \mathrm{mg}$ enzyme/g cellulose (for continuous tests with 1 and 10 hour holding time, respectively) was added at the same rate at which permeate was removed such that the reactor volume remained constant. 
Table 1: Batch hydrolysis experiment details. In all experiments the initial cellulose loading was $100 \mathrm{~g} / \mathrm{L}$.

\begin{tabular}{|c|c|c|}
\hline Experiment & $\begin{array}{c}\text { Initial cellulase enzyme loading } \\
\text { (mg enzyme/g cellulose) }\end{array}$ & $\mathrm{rpm}$ \\
\hline 1 & 25 & 100 \\
\hline 2 & 50 & 100 \\
\hline 3 & 25 & 600 \\
\hline 4 & 50 & 600 \\
\hline
\end{tabular}


Table 2: Continuous hydrolysis experiment details. In all experiments the initial cellulase enzyme loading was $50 \mathrm{mg}$ enzyme/g cellulose. Fresh feed consisting of $25 \mathrm{~g} / \mathrm{L}$ cellulose and 4 and $10 \mathrm{mg}$ enzyme/g cellulose (for continuous tests with 1 and 10 hour holding time, respectively) was added at the same rate at which permeate was removed such that the reactor volume remained constant.

\begin{tabular}{|c|c|c|c|c|c|}
\hline Experiment & $\begin{array}{c}\mathrm{C}_{0:} \\
\text { Initial } \\
\text { Cellulose } \\
\text { loading } \\
(\mathrm{g} / \mathrm{L})\end{array}$ & $\begin{array}{c}\text { Permeate } \\
\text { flow rate } \\
(\mathrm{mL} / \mathrm{min})\end{array}$ & $\begin{array}{c}\mathrm{V}_{\mathrm{R}}: \\
\text { Reactor } \\
\text { volume } \\
(\mathrm{mL})\end{array}$ & $\begin{array}{c}\tau: \\
\text { Holding } \\
\text { Time } \\
\text { (hour) }\end{array}$ & $\begin{array}{c}\xi: \\
\text { Pre- } \\
\text { holding } \\
\text { Time } \\
\text { (hour) }\end{array}$ \\
\hline 5 & 150 & 2 & 1200 & 10 & 0 \\
\hline 6 & 100 & 2 & 1200 & 10 & 0 \\
\hline 7 & 100 & 5 & 300 & 1 & 0 \\
\hline 8 & 150 & 2 & 1200 & 10 & 5 \\
\hline 9 & 100 & 2 & 1200 & 10 & 5 \\
\hline 10 & 100 & 5 & 300 & 1 & 0.5 \\
\hline
\end{tabular}




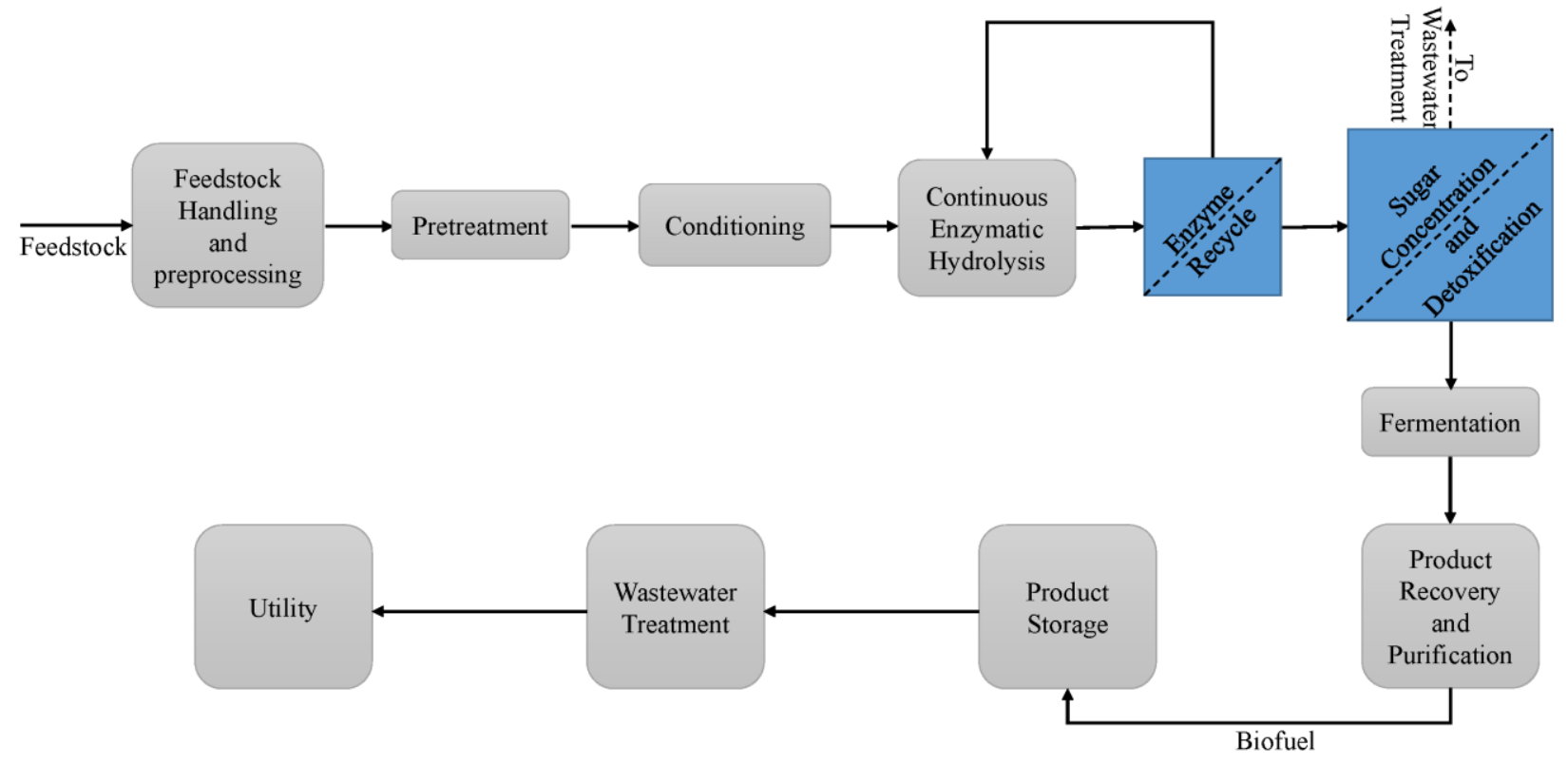

Figure 1: Schematic representation of a future lignocellulosic biomass to biofuel biorefinery. A possible continuous hydrolysis step with enzyme recycle has been included. 


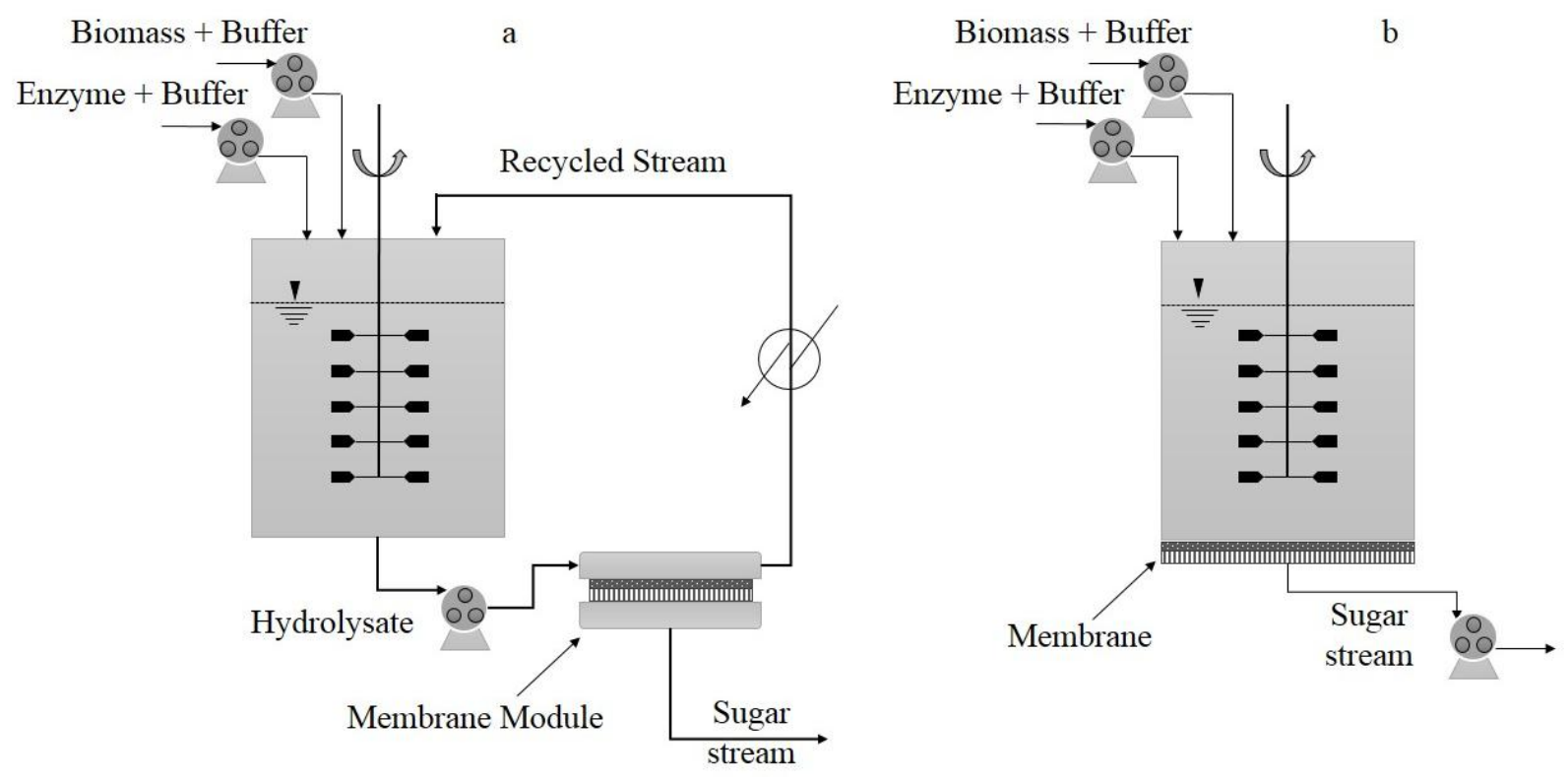

Figure 2: Schematic representation of an external loop (a) and submerged membrane reactor (b). 


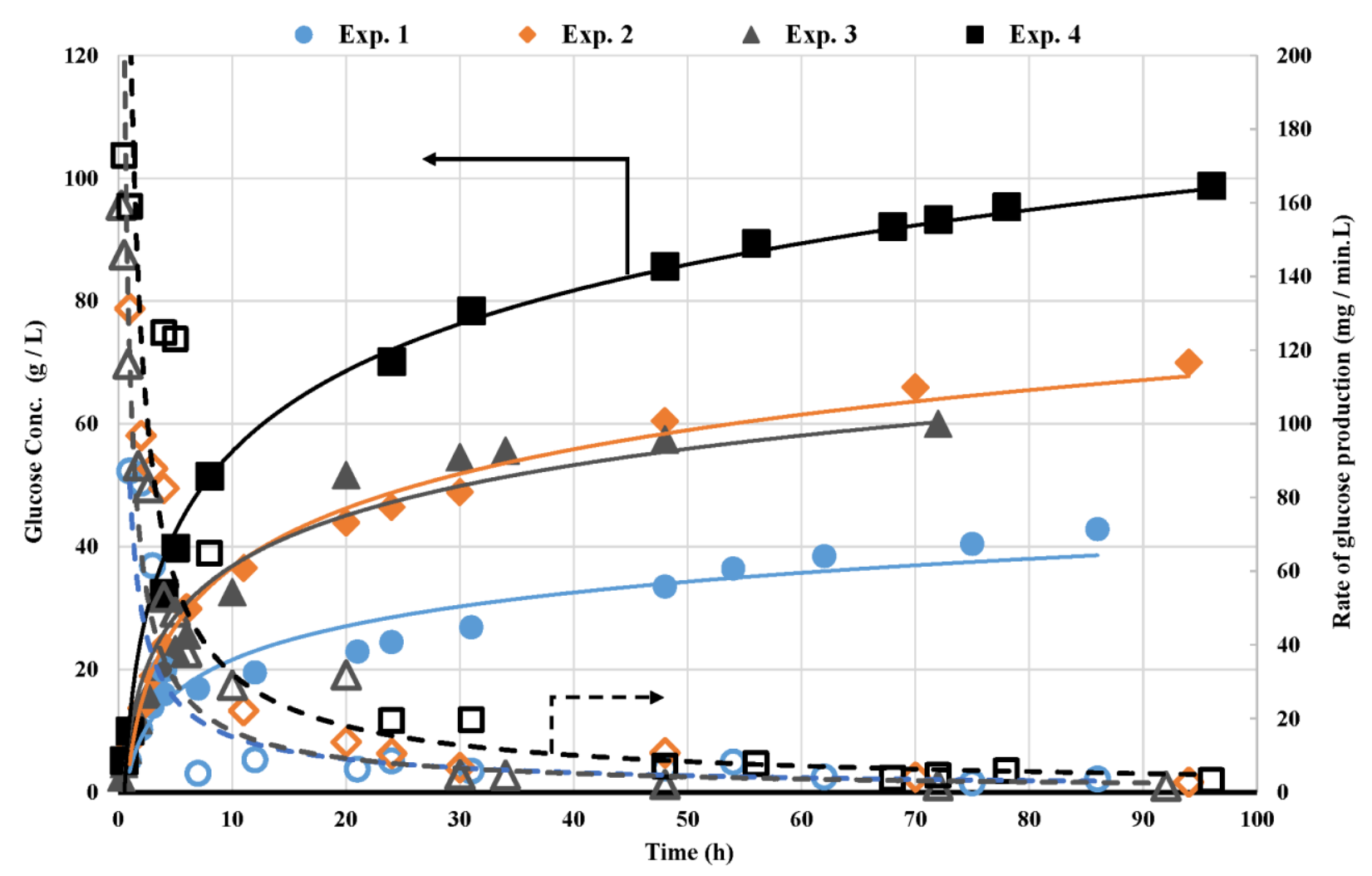

Figure 3: Batch hydrolysis results. Results are given for the 4 experiments listed in Table 1. Solid lines and filled symbols give the glucose concentration and are read using the left-hand side y-axis; dashed lines and open symbols give the rate of glucose production and are read using the right-hand side $\mathrm{y}$-axis. 

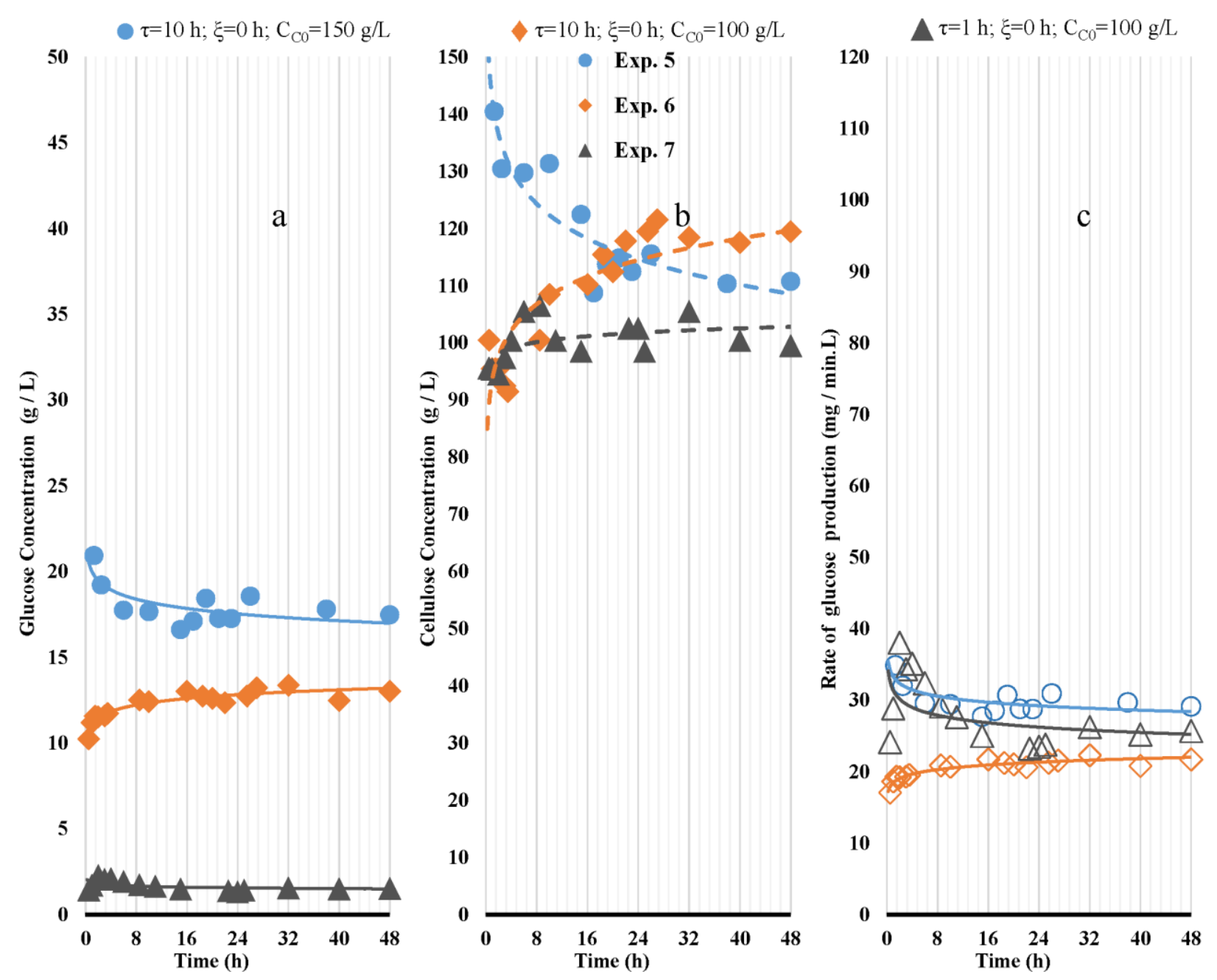

Figure 4: Continuous hydrolysis results. Results are given for experiments 5-7 listed in Table 2 which do not include a pre-holding time: (a) glucose concentration with filled symbols and solid lines; (b) cellulose concentration with filled symbols and dashed lines; (c) rate of glucose production with open symbols and solid lines. 

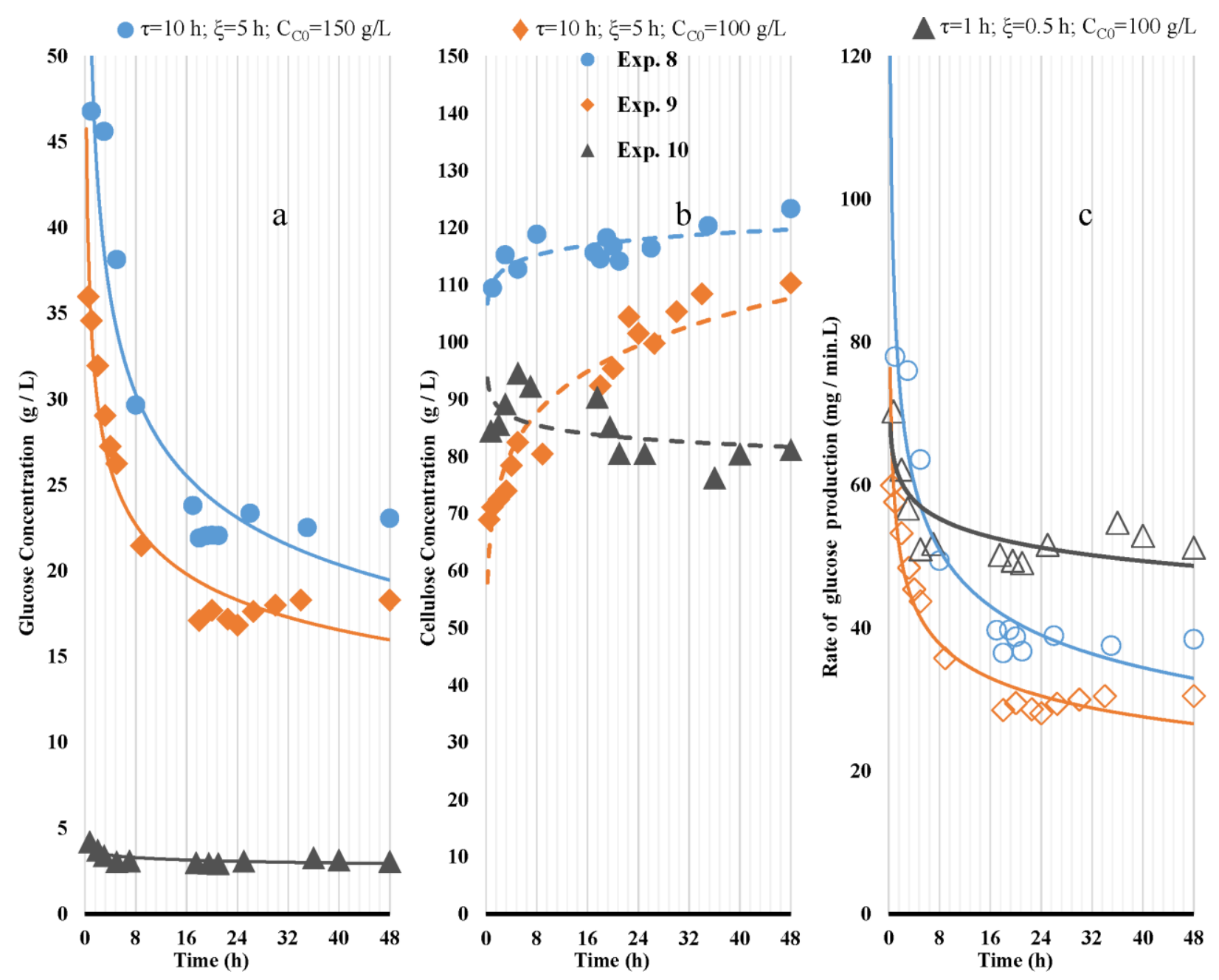

Figure 5: Continuous hydrolysis results. Results are given for experiments 8-10 listed in Table 2 which included a pre-holding time: (a) glucose concentration with filled symbols and solid lines; (b) cellulose concentration with filled symbols and dashed lines; (c) rate of glucose production with open symbols and solid lines. 